Chowdhury, N., Hicks, R. and Kreitman, N. (1972). Social Psychiatry. In

press.
Dorpat, T. L. and Ripley, S. H. (1967). Comprehensive Psychiatry, 8, 71.

Greer, S., and Bagley, C. (1971). British Medical fournal, 1, 310.

Kennedy, P. F. (1971). Epidemiological Survey of Attempted Suicide in General Practice in Edinburgh. M.D. thesis being submitted to University of Leeds.
Kessel, N. (1965). British Medical fournal, 2, 1265.

Kessel, N. and McCulloch, W. (1966). Proceedings of the Royal Society of Medicine, 59, 89.

Kreitman, N., Philip, A. E., Greer, S., and Bagley, C. R. (1969). British Fournal of Psychiatry, 115, 746.

Matthew, H., Proudfoot, A. T., Brown, S. S., and Aitken, R. C. B. (1968) British Medical fournal, 3, 489.

\title{
Glomerular Filtration Rate and Renal Plasma Flow in Long- term Juvenile Diabetics without Proteinuria
}

\section{E. MOGENSEN}

British Medical fournal, 1972, 4, 257-259

\section{Summary}

Glomerular filtration rate and renal plasma flow were examined in 16 young male non-proteinuric diabetics (mean age 28.4 years) with a duration of diabetes of over 15 years (mean duration 21.5 years.) In this selected group of long-term diabetics the glomerular filtration rate was clearly increased, the mean being $136 \mathrm{ml} / \mathrm{min}( \pm S . D$. 11.8) (normal value $114 \mathrm{ml} / \mathrm{min}( \pm 14 \cdot 1)$, being comparable to that found earlier in short-term diabetics. There was no change in renal plasma flow. It is concluded that kidney function is generally well preserved in long-term diabetics who have not developed proteinuria.

\section{Introduction}

The glomerular filtration rate is increased in early juvenile diabetes (Stalder et al., 1960; Ditzel and Schwartz, 1967; Mogensen, 1971a, 1971b, 1971c, 1971d; Mogensen, 1972) and the abnormally high filtration rate is related to the metabolic derangement seen in diabetes (Mogensen, 1971a). Kidney function is also known to decrease with the duration of diabetes. In some patients with diabetes of long duration, however, surprisingly high filtration rates are found (Mogensen, 1971b).

The present study was undertaken to examine the degree of functional renal involvement in long-term diabetic subjects without clinical proteinuria to clarify further the natural history of diabetic nephropathy.

\footnotetext{
Second University Clinic of Internal Medicine, Kommunehospitalet, Aarhus, Denmark

C. E. MOGENSEN, M.D., Registrar
}

\section{Subjects and Methods}

Sixteen young male diabetics with a duration of diabetes of more than 15 years were examined. Their mean age was 28 years $( \pm$ S.D. $5 \cdot 2)$ and the mean duration of diabetes 21.5 years $( \pm 7 \cdot 3)$. All were insulin dependent. Mean body surface area was $1.82 \mathrm{~m}^{2}( \pm 0 \cdot 12)$. None had proteinuria as judged by the Albustix test on several urine samples. The mean fasting plasma glucose on the day of the clearance test was $197 \mathrm{mg} / 100 \mathrm{ml}$ $( \pm 82)$, indicating that most of the patients were not strictly controlled. Pertinent clinical data are given in the Table, including the degree of retinopathy according to the classification of Jensen and Lundbaek (1971). Control subjects were 35 normal young men (medical students) and 24 young male diabetics with diabetes of short duration (mean 4.6 years $( \pm 2 \cdot 7)$, range 1-12 years). The mean age of the normal subjects and of the shortterm diabetics was $25( \pm 1 \cdot 9)$ and 23 years $( \pm 5 \cdot 1)$ respectively. Their mean body surface areas were $1.91( \pm 0.11)$ and $1.81 \mathrm{~m}^{2}$ $( \pm 0 \cdot 13)$ respectively.

Clearance Tests. - The glomerular filtration rate was measured by ${ }^{125 I}$ iothalamate and renal plasma flow by ${ }^{131}$ I-Hippuran clearance using a constant infusion technique described previously (Mogensen, 1971b). Three or four clearance periods lasting 20 minutes were used in each test. Labelled iothalamate and Hippuran are reliable substances for measuring glomerular filtration rate and renal plasma flow (Magnusson, 1962; Elwood et al., 1967; Elwood and Sigman, 1967; Summers et al., 1967; Skov, 1970; Mogensen, 1971b). Results were corrected to 1.73 $\mathrm{m}^{2}$ body surface area. Plasma glucose was measured using a glucose oxidase method (Christensen, 1967). Tests were performed in the morning in the fasting state. The diabetics had been given their last insulin in the morning or afternoon the day before the clearance test.

\section{Results}

Results in the 16 long-term diabetics without proteinuria are given in the Table. Glomerular filtration rate and renal plasma

Kidney Function in 16 Non-proteinuric Long-term Diabetics (Duration of Diabetes more than 15 Years)

\begin{tabular}{|c|c|c|c|c|c|c|c|}
\hline $\begin{array}{l}\text { Case } \\
\text { No. }\end{array}$ & $\begin{array}{c}\text { Age } \\
\text { (Years) }\end{array}$ & $\begin{array}{c}\text { Duration of Diabetes } \\
\text { (Years) }\end{array}$ & $\begin{array}{c}\text { Stage of } \\
\text { Retinopathy }\end{array}$ & $\begin{array}{c}\text { Plasma Glucose } \\
(\mathrm{mg} / 100 \mathrm{ml})\end{array}$ & $\begin{array}{l}\text { Glomerular Filtration } \\
\text { Rate (ml/min) }\end{array}$ & $\underset{(\mathrm{ml} / \mathrm{min})}{\text { Renal Plasma Flow }}$ & $\begin{array}{l}\text { Filtration } \\
\text { Fraction }\end{array}$ \\
\hline $\begin{array}{r}1 \\
2 \\
3 \\
4 \\
5 \\
6 \\
7 \\
8 \\
9 \\
10 \\
11 \\
12 \\
13 \\
14 \\
15 \\
16\end{array}$ & $\begin{array}{l}23 \\
26 \\
27 \\
25 \\
27 \\
38 \\
26 \\
27 \\
27 \\
26 \\
39 \\
24 \\
30 \\
38 \\
25 \\
27\end{array}$ & $\begin{array}{l}17 \\
20 \\
26 \\
20 \\
22 \\
37 \\
22 \\
15 \\
16 \\
19 \\
37 \\
19 \\
28 \\
15 \\
16 \\
15\end{array}$ & $\begin{array}{r}\mathbf{0} \\
\mathbf{I} \\
\mathbf{I} \\
\mathbf{I I} \\
\mathbf{I} \\
\mathbf{I} \\
\mathbf{0} \\
\mathbf{0} \\
\mathbf{0} \\
\mathbf{I} \\
\mathbf{I I I} \\
\mathbf{I} \\
\mathbf{I I I} \\
\mathbf{I I I} \\
\mathbf{I} \\
\mathbf{I}\end{array}$ & $\begin{array}{r}169 \\
233 \\
239 \\
314 \\
241 \\
178 \\
76 \\
264 \\
354 \\
220 \\
60 \\
171 \\
203 \\
128 \\
91 \\
219\end{array}$ & $\begin{array}{l}121 \\
125 \\
145 \\
144 \\
151 \\
133 \\
127 \\
160 \\
128 \\
132 \\
144 \\
133 \\
119 \\
129 \\
151 \\
134\end{array}$ & $\begin{array}{l}470 \\
613 \\
642 \\
543 \\
616 \\
470 \\
498 \\
688 \\
544 \\
554 \\
570 \\
573 \\
512 \\
564 \\
606 \\
577\end{array}$ & $\begin{array}{l}0.26 \\
0.20 \\
0.23 \\
0.27 \\
0.25 \\
0.28 \\
0.26 \\
0.23 \\
0.24 \\
0.24 \\
0.25 \\
0.23 \\
0.23 \\
0.23 \\
0.25 \\
0.23\end{array}$ \\
\hline Mean \pm S.D. & $28 \cdot 4 \pm 5 \cdot 2$ & $21 \cdot 5 \pm 7 \cdot 2$ & & $197 \cdot 5 \pm 81 \cdot 7$ & $136.0 \pm 11.8$ & $565 \cdot 0 \pm 60 \cdot 2$ & $0.243 \pm 0.019$ \\
\hline
\end{tabular}


flow in the long-term diabetics are shown in Figs. 1 and 2, together with results from normal subjects and short-term diabetics. The glomerular filtration rate was significantly increased in both short-term and long-term non-proteinuric diabetics, being $21.9 \%$ and $19.3 \%$ greater than normal. In comparison with normal values there was no change in renal plasma flow, and there was no difference between the two groups of diabetics. The results related to duration of diabetes in the longterm diabetics are given in Figs. 3 and 4. Probably there was no correlation with the duration of diabetes, and kidney function

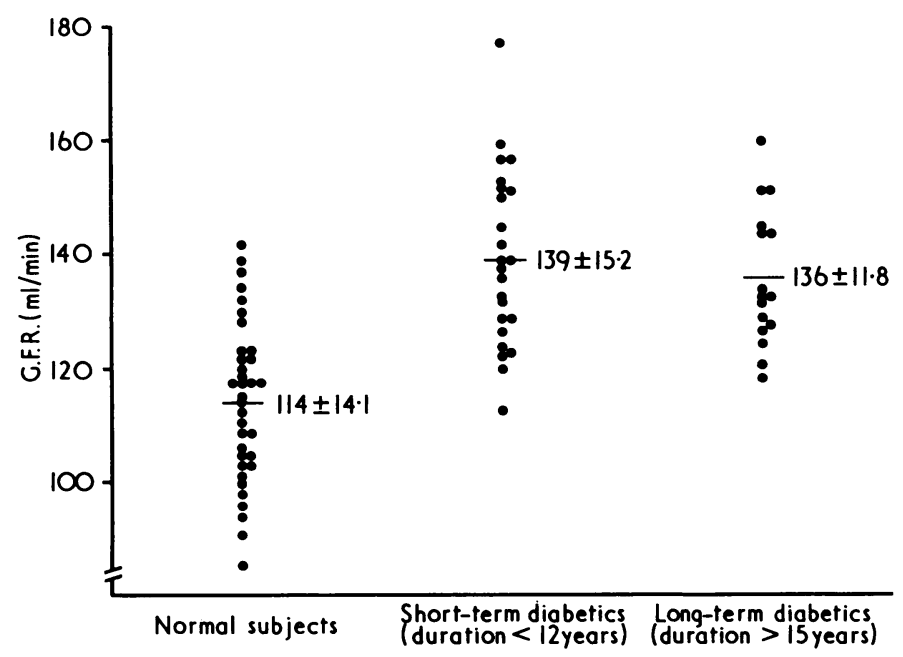

FIG. 1-Glomerular filtration rate (G.F.R.) in normal and non-proteinuric diabetic subjects (125 I-iothalamate clearance).

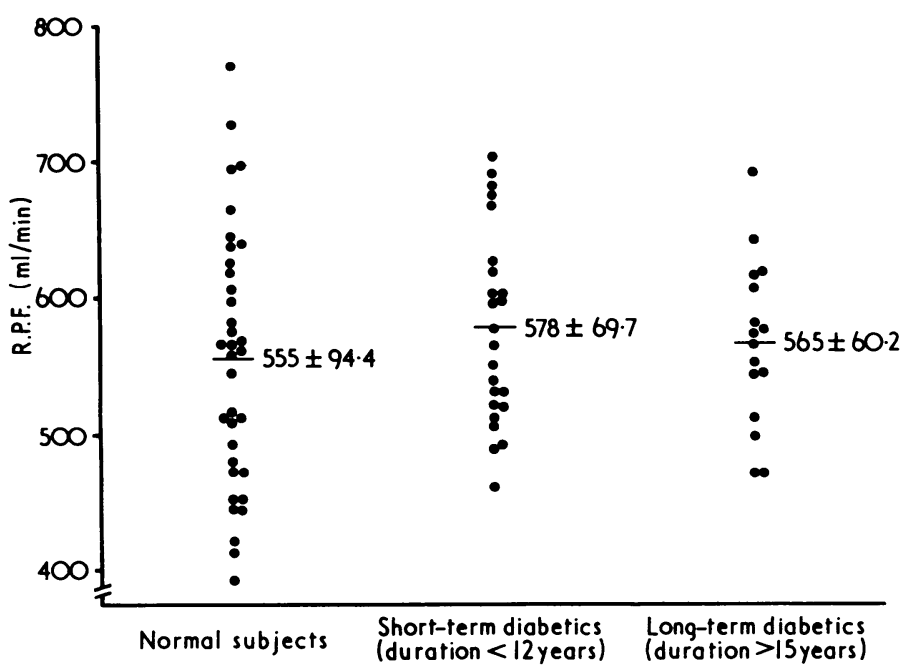

FIG. 2-Renal plasma flow (R.P.F.) in normal and non-proteinuric diabetic subjects (181I-Hippuran clearance).

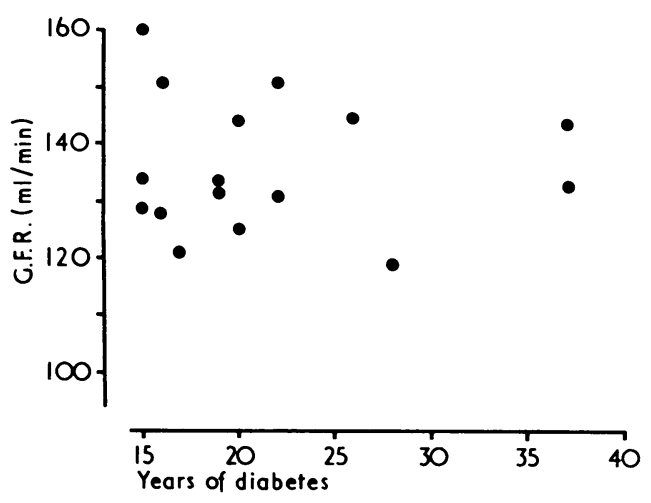

FIG. 3-Glomerular filtration rate in 16 male diabetic non-proteinuric patients with diabetes for more than 15 years.

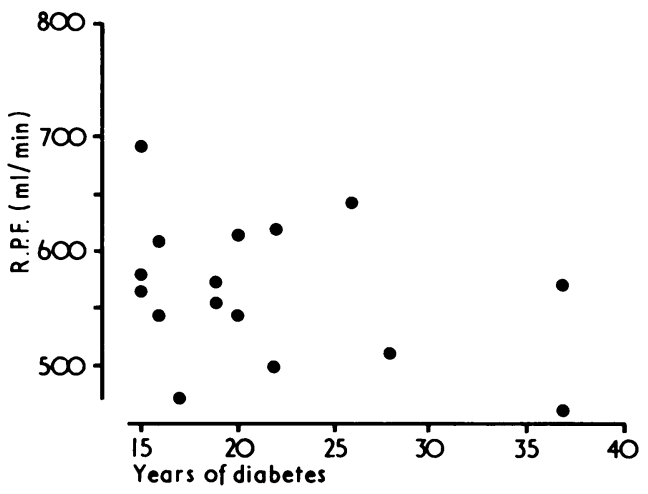

FIG. 4-Renal plasma flow in 16 male diabetic non-proteinuric patients with diabetes for more than 15 years.

was not related to the plasma glucose level. There was no correlation between the degree of retinopathy and kidney function.

The mean percentage coefficients of variance for the individual results in the clearance periods were $\mathbf{7 . 0}$ for glomerular filtration rate and 6.5 for renal plasma flow, or of the same order of magnitude as found in normal subjects and short-term diabetics (Mogensen, 1971b).

\section{Discussion}

The present study shows that in young male diabetics with long-standing diabetes but without proteinuria kidney function is well preserved and at the same high level as in short-term diabetics. Several studies have shown that the glomerular filtration rate is abnormally high in early juvenile diabetics (Stalder et al., 1960; Ditzel and Schwartz, 1967; Mogensen, 1971a, 1971b, 1971c, 1971d; Mogensen, 1972). This abnormally high rate is associated with the metabolic derangement in diabetes, since the glomerular filtration rate can be brought to normal or almost normal during strict insulin treatment in newly diagnosed diabetics (Mogensen, 1971a). Kidney function decreases with the duration of diabetes (Mogensen 1971b). In the present selected group of long-term diabetics characterized by not having developed proteinuria this decrease in kidney function was, however, not found. Indeed, there was no correlation with the duration of diabetes (Figs. 3 and 4). Thus the morphological alterations in the kidney are not only clinically but also functionally mute over many years.

The present results, of course, do not indicate the ultimate outcome of the patients. Diabetic nephropathy is a major cause of death in juvenile diabetics (Lundbaek, 1953, 1965), and our results do not oppose this concept. It appears from the present results that kidney function in diabetics is not characterized by a slow and gradual fall in glomerular filtration rateand renal plasma flow with the duration of diabetes. It seems to remain stable for many years, with a subsequent, rather rapid decline when nephropathy becomes clinically obvious (Deckert and Poulsen, 1968).

In the present study, where ${ }^{181}$ I-Hippuran was used for evaluating renal plasma flow, no significant increase was found in early diabetes although mean values were higher than normal. Thus the small rise previously found by aminohippuric acid clearance (Mogensen, 1971b) is probably of borderline significance.

The initial morphological change in the diabetic glomerulus is an increase in the thickness of the glomerular basement membrane, which can be shown after a duration of diabetes of one and a half years if an exact morphometric technique is used ( $\varnothing$ sterby, 1972). The increase in thickness probably continues gradually over the years, and in the present patients, with a mean duration of diabetes of 21.5 years, thickness was probably about double the value obtained in normal subjects (Lazarow, 1969; $\varnothing$ sterby, 1971). The extent of other glomerular lesions is difficult to evaluate in these selected patients since no renal biopsy 
specimens were taken. Obviously, however, the morphological changes are not reflected by changes in function as judged by glomerular filtration rate and renal plasma flow.

The high level of kidney function generally found in diabetics without proteinuria should be considered when evaluating results in proteinuric diabetics. Thus values in the lower normal range might be abnormal for diabetics, since they should be compared with the higher level in non-proteinuric diabetics.

It is perhaps surprising that an increased glomerular filtration rate has not been reported previously in long-term diabetics without proteinuria. Of course, initially patients with clinically obvious nephropathy were investigated, and here decreased glomerular filtration rate and renal plasma flow are major findings (Corcoran et al., 1948; Rotertson et al., 1951; Brun et al., 1953; Lundbaek, 1953; Bucht et al., 1956; Latotzki, 1958; Thomsen, 1965; Lüdtke, 1966). In the present study welldefined comparable groups were examined, the mean ages of the long-term diabetics and normal subjects being 28 and 25 years respectively. The present studies were thus confined to young subjects; hence the possible influence of age-dependent vascular disease is minimized.

Early changes in kidney function may be important in the development of diabetic nephropathy (Stalder et al., 1960; Ditzel and Junker, 1972), and increased permeability and possibly increased filtration pressure might lead to degenerative changes in the glomerulus. At the present time this important question is not fully clarified. Nevertheless, the increased glomerular filtration rate of early diabetes is associated with normal permeability to large molecular dextran molecules (Mogensen, 1971a). Furthermore, normal urinary albumin excretion has been found in most juvenile diabetics without proteinuria irrespective of the duration of diabetes, and this also suggests normal glomerular permeability to macromolecules (Mogensen, 1971e).

The present study showed that increased glomerular filtration rate and increased filtration fraction can be found in diabetics of very long duration. The glomerular filtration rate and the filtration fraction have probably been at the same high level for many years without causing clinical nephropathy. Radiological studies in short-term juvenile diabetics with increased glomerular filtration rates have shown that the kidney is enlarged (Mogensen and Andersen, 1972). These findings suggest that increased kidney size is important in the high glomerular filtration rate of early diabetes. The increased rate does not necessarily reflect vascular changes in the glomerular capillary wall.
In my opinion these findings speak against the concept that the abnormalities in kidney function play a major part in the development of the morphological alterations of the diabetic nephropathy.

My thanks are due to Mrs. Bodil Willumsen for her sikilful technical help. The investigations were supported by grants from Statens laegevidenskabelige Forskningsråd, Denmark.

\section{References}

Brun, C., Gormsen, H., Hilden, T., Iversen, P., and Raaschou, F. (1953). American fournal of Medicine, $15,187$.

Bucht, H., Ek, J., and Werkö, L. (1956). Scandinavian Fournal of Clinical and Laboratory Investigation, 8, 309.

Christensen, N. J. (1967). Scandinavian fournal of Clinical and Laboratory Investigation, 19, 379.

Corcoran, A. C., Taylor, R. D., and Page, I. H. (1948). Annals of Internal Medicine, 28, 560 .

Deckert, T., and Poulsen, J. E. (1968). Acta Medica Scandinavica, 183, 351.

Ditzel, J., and Junker, K. (1972). British Medical fournal, 2, 13.

Ditzel, J., and Schwartz, M. (1967). Diabetes, 16, 264.

Elwood, C. M., and Sigman, E. M. (1967). Circulation, 36, 441.

Elwood, C. M., and Sigman, E. M. (1967). Circulation, 36, 441. Radiology, 40, 581 .

Jensen, V. A., and Lundbaek, K. (1971). In Handbuch des Diabetes Mellitus, ed. E. F. Pfeiffer, vol. 2, p. 659. Munich, Lehmanns.

Latotzki, H. (1958). Zeitschrift für klinische Medizin, 155, 158.

Lazarow, A. (1969). Proceedings of the Sixth Congress of the International Diabetes Federation, 1967, ed. J. Östman, p. 301. Amsterdam, Excerpta Medica.

Ludtke, E. (1966). Zeitschrift für innere Medizin, 21, 134.

Lundbaek, K. (1953). Long-term Diabetes. Copenhagen, Munksgaard.

Lundbaek, K. (1965). In On the Nature and Treatment of Diabetes, ed. B. S. Leibel and G. A. Wrenshall, p. 436. Amsterdam, Excerpta Medica.

Magnusson, G. (1962). Acta Medica Scandinavica, 117, Suppl., 378.

Mogensen, C. E. (1971a). Scandinavian Fournal of Clinical and Laboratory Investigation, $\mathbf{2 8 , 7 9 .}$

Mogensen, C. E. (1971b). Scandinavian Fournal of Clinical and Laboratory Investigation, 28, 91 .

Mogensen, C. E. (1971c). Scandinavian Fournal of Clinical and Laboratory Investigation, 28, 101 .

Mogensen, C. E. (1971d). Scandinavian Fournal of Clinical and Laboratory Investigation, 28, 177.

Mogensen, C. E. (1971e). Scandinavian Fournal of Clinical and Laboratory Investigation, 28, 183

Mogensen, C. E. (1972). Danish Medical Bulletin, 19, Suppl., 3.

Mogensen, C. E., and Friis Andersen, M. J. (1972). To be published.

Osterby, R. (1971). In Microcirculatory Approaches to Current Therapeutic Problems, eds. J. Ditzel and D. H. Lewis. Basel, Karger.

Østerby, R. (1972). Diabetologia., 8, 84.

Robertson, J. A., Gray, C. H., and Banes, A. H. (1951). Archives of Internal Medicine, 87,570 .

Skov, P. E. (1970). Acta Medica Scandinavica, 187, 419.

Stalder, G., Schmid, R., and Wolff, M. V.'(1960). Deutsche medizinische Wochenschrift, 85, 346.

Summers, R. E., Concannon, J. P., Weil, C., and Cole, C. (1967). Fournal of Laboratory and Clinical Medicine, 69, 919.

Thomsen, Aa. Chr. (1965). The Kidney in Diabetes. Copenhagen, Munksgaard.

\title{
Idiopathic Palsy of the Recurrent Laryngeal Nerve: A Transient Cranial Mononeuropathy
}

\author{
J. N. BLAU, RUMY KAPADIA
}

British Medical fournal, 1972, 4, 259-261

no major disease during the subsequent one to eight years.

\section{Summary}

Unilateral vocal cord palsy can be a benign condition with a reasonable chance of spontaneous recovery. Analysis of 21 selected patients has shown that 5 recovered completely and another 5 improved within months of the onset. The remaining 11 patients developed

National Hospital, Queen Square, London W.C.1

J. N. BLAU, M.D., F.R.C.P., Consultant Physician

Royal National Throat, Nose and Ear Hospital, London W.C.1 R. KAPADIA, F.R.c.s., Senior Registrar

\section{Introduction}

Foley (1969) coined the elegant term "the cranial mononeuropathies" in a leading article on transient cranial nerve palsies and cited the 3rd, 5th, 6th, 7th, 8th, and 12th nerves. Although idiopathic palsy of the recurrent laryngeal nerve is well recognized by laryngologists the proportion of patients who recover is less widely appreciated. In spite of negative investigations these patients are often suspected of harbouring mediastinal malignancy by the E.N.T. surgeon or the general physician or neurologist who may be consulted. 